thrown into sharp relief a number of ethical, legal and social issues. This book is concerned with discrimination because of sexual orientation, the alienation of some groups in society such as drug users, theological responses to minority groups and doctors' responsibilities concerning confidentiality. Additional chapters address the distortions and simplifications which occur in the popular press about complex issues such as sexuality and HIV infection and there is a particularly clear chapter on the legal aspects of being HIV-positive in this country and the United States.

A more enlightened attitude amongst health-care workers, including doctors and policy-makers, will be encouraged if the discrimination encountered amongst AIDS patients is placed in a more general context - which this book sometimes fails to do. I feel this book needs a clear statement of the ethical principles involved and their application to the topics discussed in each chapter. The intended readership is not explicitly stated but the issues are important to a wide audience. Some of the more contentious peripheral issues discussed in the book may detract from the important message for a general readership.

This book results from a conference held in 1986 and its delay in publication gives a dated feel to some of the discussion, for example, new advances in technology have rendered the problem of false positive and negative HIV tests virtually obsolete. Many doctors would also accept that asymptomatic HIV seropositive individuals can now be given treatment which will prolong life. This is bound to influence judgements about the value of HIV testing. The bibliography is often obscure and mainly pre-1986 - few readers for instance, will have access to the abstract of the Third International Congress on AIDS held in Washington DC.

This book addresses extremely important issues which confront all of us concerned about HIV infection. It should be widely available in university and medical school libraries and it is inexpensive enough for many of us to buy and ponder over.

DR BRIAN G GAZZARD Consultant Physician and AIDS Co-ordinator, Westminster Hospital, Dean Ryle Street, Horseferry Road, London SWIP 2AP.

\section{Social Science Perspectives on Medical Ethics}

Edited by George Weisz, 290 pages, Philadelphia, $\$ 17.95 \mathrm{sc}$, University of Pennsylvania Press, 1990

This interesting book is based on a selection of papers originally presented at a 1988 meeting of social scientists and ethicists carrying out research on issues related to medical ethics. Most contributors draw on data related to North America but Weisz writes on the origins of medical ethics in France, Stacey on the General Medical Council in Britain and Lock on heart transplantation in Japan.

The book has two purposes. The first is to present research on how ethical issues are handled in particular institutional or cultural settings. Decision-making and issues of informed consent are examined in the areas of neonatal care, family planning and psychiatry. Here, the researchers' approach is mainly ethnographic. This allowed them to examine how ethical decisions were made in practice. Other papers look at policy-making in areas of public concern. Rothman examines the process by which the issue of experimentation involving human subjects became politicised in the United States, while Fox traces the evolution of bioethics. These chapters make fascinating case-studies available to a wider audience. They illustrate the dynamics of decision-making and the power relationships between interest groups. It comes as no surprise that medicine dominates but the nuances are important in developing a knowledge of the facets of power.

The book's second purpose is to help bridge the divide between the ethics and social science disciplines. A number of papers draw attention to the limitations of moral theory with its emphasis on individualism and abstract concepts. They point to the importance of examining how mediating structures and institutions such as class, ethnicity, family and profession may expose people to different obligations. They argue for a 'contextualised morality'. However, the problem remains that this is social science rather than ethics.

The issue clearly dogged the conference and could have been more fully addressed in the collection. In a somewhat tantalising introduction, Weisz comments on the dynamics of the conference itself, mentioning 'some' friendly exchanges between ethnographers and ethicists and the 'surprisingly silent' anthropologists. He looks to ethnography as a possible method for developing the study of morality in practice where there could be common ground between social science and ethics, between the 'is' and the 'ought' in social life. No doubt a structural sociologist would comment that behind the academic endeavours lie concerns about 'turf' and the ownership of knowledge.

JUDITH ALLSOP, Reader in Health Policy, Department of Social Science, South Bank Polytechnic, Borough Road, London SE1 OAA.

\section{Power to the People}

Edited by Liz Winn, 91 pages, London, £7.50, King's Fund Centre, 1990

A coterie of a dozen authors, not medically qualified but working earnestly 'in and around health services', have each produced a chapter about their own sphere of activity to form an 'anthology of approaches which are trying, not just to involve users of the health and social services, but to empower them when they come into contact with these services'. Their 'initiatives are concerned with shifting the balance of power toward those using services and away from those providing them' and we learn that 'where initiatives have succeeded they seem to need at least a partial erosion of service provider monopoly on ideas, debate and decision-making in favour of users'. The booklet's title and its depiction in graffitti form, as well as these preliminaries, hint at revolution. Those who believe our services stand in need of just such a thing, as well as others who think increased funding alone to be the sovereign remedy, may all find in the text items of interest.

Topics include 'empowering older people in respect of their own health care'; tailoring services for those with learning difficulties to what they need and want; 'user group involvement' in mental health services to enable users 'to exercise a greater control over their own lives'; 'citizen advocacy' and an 'advocacy agency'; and what information is necessary to choose a GP or hospital.

The authors would have furthered their cause had their communicative skills been evident to readers. Instead, 
their prose is turgid, jargon-strewn and benevolently elitist; all of which are grave impediments for those they seek to convert. 'We need to talk clearly and simply and avoid jargon', they exhort but they do not. 'Ageism', 'outreach exercises', 'advocacy relationship' and much else make for a halting narrative. With one term, 'self advocate', we learn 'there is a danger that if definitions are drawn too tightly too early on, outsiders may end up setting the agendas and marking out the boundaries of what is and what might happen'. It is doubtful if this approach will breach 'the professional resistance and organisational blocks' which the authors insist 'still need to be overcome'. If words cannot express their meaning, little else is likely to.

'Many professional groups remain reluctant to share the information they have; some believe doctors alone should make decisions about patients; others are afraid of any exposure that will reveal their own levels of competence and performance.' 'Much of this information simply does not exist at present; not even in a form useful to managers and clinicians, let alone to users.' This is very true. Fashionable audit measures numbers (of days, prescriptions, referrals etc) but it has yet meaningfully to tackle quality. The measures of competence and performance (as the authors put it), are to be deduced, each time a person sees a doctor, from answers to the following questions: Has this person benefited, not benefited, or been made worse? To date, these questions are not being asked, let alone their answers made public.

Unfortunately this booklet suffers from imbalance; for while it contains, usefully, no medical prejudice, it simultaneously contains no medical insight. It holds one main belief: that if users have more information, more power to influence, then the users of the health and social services will naturally benefit. They may sometimes. But the premise is dangerously naive. Illogical though it may seem, more user information and power can and does lead to unreasonable expectations, to mistaken views of what is needed, and to servile doctors providing unnecessary items for what their patients perceive, in their increased but still incomplete awareness, as necessary. Thousands of drugs, referrals and even operations are annually and eventually shown (by the patient) to have been unhelpful (at best) - although in the short term they were the 'something' that the patient wanted and was pacified with. Does this mean that user ignorance is bliss? On the contrary. Equality between user and professional is highly desirable. But the services will become 'user friendly' (the authors' term) only when the professionals are dishabituated from practising as if by rote, under cover of 'professionalism'. Medical excellence will come from meaningful accountability which, in my view, is best carried out by professionals as well as users; perhaps, in the present absence of such an initiative, by a medical inspectorate.

DR WILLIAM G PICKERING, MBBS, MRCP, MRCGP, AFOM, DCH, DRCOG 7 Moor Place, Gosforth, Newcastle upon Tyne NE3 4AL.

\section{Educating Competent and Humane Physicians}

Hugh Hendrie and Camille Lloyd, 223 pages, Indiana, US\$29.95, Indiana University Press, 1990

There is a common and justified belief that we are in danger of producing doctors who, whilst being good at the technical aspects of medicine, are not sufficiently caring about, and sensitive to, their patients' needs. The increasing concern with the teaching both of ethics and communication skills as part of the student curriculum is a welcome development in recent years. In Europe we are slowly following where North America leads. The development of medical ethics teaching has been largely at the instigation of philosophers, theologians and lawyers. In some places the syllabus develops from a consideration of real patients, in other places ethical principles are used as the starting point. In either case the content tends to be related closely to the concerns of moral philosophy.

If one were to ask why medical students should be taught ethics then I imagine that the final justification would be that such teaching is likely to help in producing better doctors. And better doctors would be doctors who are likely to be more caring of their patients, more sensitive to the moral aspects of medical practice.

This excellent book is not primarily about how one would teach medical ethics and communication skills. It goes straight to the issue of how students should be trained in order to maximise the chance that they become caring and humane doctors. The points that it raises complement any discussion of the teaching of ethics.

The 12 essays have been well chosen and edited so that the book as a whole has a structure and an argument. The argument starts with reviews of the evidence that social and psychologica factors are of great importance both in the aetiology and management of physically ill people. Doctors can improve management if they are able to understand the role these factors are playing and able to influence patients through good and sensitive communication. One of the pleasures in reading this book is finding interesting ideas sparkling from within the text. For example, to learn of the need for doctors to learn communication skills comes as no surprise, but the suggestion that doctors should teach patients how to communicate sets the mind thinking down new avenues.

The second part of the book looks at current medical education. Two important criticisms are made of current practice. The first is that medical training tends to emphasise excessively the very ill patient. Students learn to undervalue the importance of less severe illness, and they have little experience of long-term problems General practitioners will recognis here one of the problems the experience with hospital-based medicine: the excessively optimistic accounts of an acute intervention which when seen in the context of the patient's longer-term welfare appears useless or even detrimental.

The second point is that if medical students are going to be caring of patients, then they themselves must be treated in a humane fashion. More generally this assertion can be expressed by saying that the relationship between the students and their teachers should mirror, in many ways, the relationship that should exist between doctor and patient. This view has important implications for the teaching of medical ethics for it suggests that we should be paying as much attention to the structures and relationships between teachers and taught, as we should to the actual content of our courses.

The last part of the book looks both at the past, and the future. Of particular interest with reference to the themes of the second part is the preliminary report of an intervention study carried out at the Memorial Sloan-Kettering Cancer Center. Essentially the intervention involved giving more help and support to the junior medical staff, and the preliminary results suggest this had a beneficial effect on patient care. This 